MANFRED CHRISTL“", ERICH BRUNA", HOLFGANG R. ROTH*, AND HANS-HERNER LENNARTZ"

Institut für Organische Chemie der Universität Hürzburg`,

Am Hubland, D-8700 Würzburg, Federal Republic of Germany

Fakultät für Chemie der Universitat Bochum",

Postfach 102148, D-4630 Bochum 1. Pederal Republic of Germany

(Received in Belgium 8 August 1988)

\begin{abstract}
Abatract: The addition of benzvalene (1) to diazomethane, diazoethane, 2diazopropane, phenyldiazomethane, and diphenyldiazomethane afforded the 1-pyrazolines $2 a-g$ in good yields. By means of competition experiments, the relative reactivities of benzvalene ( $q$ ) and norbornene with regard to the relative reactivities of benzvalene ( 1 ) and norbornene with regard to valene reacts about twice as fast as norbornene with both diazoalkanes cannot be rationalized on the basis of frontier orbital energies. On direct photolysis, the pyrazolines 2 - 0 were converted into the tetracyclol $4.1 .0 .0^{2} \cdot 0^{3}$, s heptanes $4 a-g$ exclusively. These compounds gave the $1,3,5$-cycloheptatrienes $5 a, b, d, 0, g$ in high yields on treatment with silver ions, thus providing better access to 7,7-dimethyl-(5d) and 7,7diphenylcycloheptatriene (5g) than before. Surprisingly, the latter compound is in equilibrium with a substantial quantity of the norcaradiene form. - The heat of reaction for the rearrangement of a to 5 a has been determined, which allows to derive the heat of formation of tetracyclo(4. 1.0.0 $0^{2} \cdot 4 \cdot 0^{3}, 3$ ) heptane $(4 a)$.
\end{abstract}

The most generally applicable methods for the synthesis of 1,3,5-cycloheptatriene derivatives are reactions of the tropylium cation with nucleophiles and the addition of carbenes to benzene." While the former can give unequivocally only 7monosubstituted cycloheptatrienes, the latter is also suitable for the preparation of certain derivatives disubstituted in the 7-position. However, many carbenes do not react with benzene or give products only in low yields. Obviously, 7,7-dimethylcycloheptatriene (5d) cannot be obtained via this route, since it has exclusively been prepared by using other approaches. ${ }^{2} 3$ Formed in low yield on thermolysis or photolysis of diphenyldiazomethane in benzene, 7,7-diphenylcycloheptatriene (5g) appears in the literature for the first time in 1988. ${ }^{4}$ He wish to report here a three-step reaction sequence rendering cycloheptatrienes with one or two methyl or phenyl substituents in the 7-position accessible in good yiejds. This method demonstrates a utilization of benzvalene as benzene equivalent.

1,3-Dipolar cycloaditions of diazoalkanes with bengvalenes

As early as 1973, we described the addition of diazomethane to benzvalene. "The yield of 1-pyrazoline $2 a$ has now been increased considerably, and in addition diazoethane, 2-diazopropane, phenyldiazomethane, and diphenyldiazomethane have been found to give the corresponding pyrazolines $2 \mathrm{~b}-\mathrm{g}$ in good yields. In the cases of diazoethane and phenyldiazomethane, the ratios of the diastereomers $2 \mathrm{~b}: 2 \mathrm{c}=1.7$ : 1.0 and $2 e: 2 f=1.5: 1.0$, respectively, indicate only a minor stereoselectivity.

The structure of the 1 -pyrazolines 2 is established unambiguousiy by analytical and spectral data. The stereochemical assignment within the isomeric pairs $2 b, c a n d$ 2e, $f$ is based on the magnitude of the coupling constants ${ }^{3} \underline{J}_{3}, 3$. in the "H-NKR 
spectra (see Table 1) and on the $\gamma$-gauche effect of the endo-3-substituent ( $R^{2}$ ) on the chemical shift of C-4 in the " ${ }^{3} \mathrm{C}-\mathrm{NMR}$ spectra (see Table 2). Although C-5 and C-7 match each other rather closely, their signals can be distinguished by means of long-range ${ }^{3} \mathrm{C}-\mathrm{H}$ coupling constants as noted earlier for related tricyclo[3.1.0.02, ']hexane derivatives.' Similarly, the absorptions of c-4 and C-6 differ markedly in their fine structure with that of $\mathrm{C}-4$ being much better resolved.

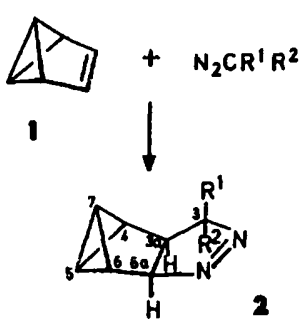

\begin{tabular}{|c|c|c|c|c|c|}
\hline diazoalkane & $\mathbf{R}^{2}$ & $R^{2}$ & product & yield & $(x)$ \\
\hline $\mathrm{N}_{2} \mathrm{CH}_{2}$ & $\mathbf{H}$ & $\mathbf{H}$ & $2 a$ & & 83 \\
\hline \multirow[t]{2}{*}{$\mathrm{N}_{2} \mathrm{CHCH}_{3}$} & $\mathbf{H}$ & $\mathrm{CH}_{\mathbf{J}}$ & $2 b$ & \multirow{2}{*}{$(58)$} & 31 \\
\hline & $\mathrm{CH}_{3}$ & $\mathrm{H}$ & 20 & & \\
\hline $\mathrm{N}_{2} \mathrm{C}\left(\mathrm{CH}_{3}\right)_{2}$ & $\mathrm{CH}_{3}$ & $\mathrm{CH}_{3}$ & $2 d$ & \multirow{3}{*}{$(73)$} & 93 \\
\hline \multirow[t]{2}{*}{$\mathrm{N}_{2} \mathrm{CHC} 6 \mathrm{Hs}$} & H & $\mathrm{C}_{6} \mathrm{Hg}$ & $2 \bullet$ & & 44 \\
\hline & $\mathrm{C}, \mathrm{H}_{3}$ & $\mathbf{H}$ & $2 r$ & & \\
\hline $\mathrm{N}_{2} \mathrm{C}\left(\mathrm{C}_{6} \mathrm{H}_{5}\right)_{2}$ & $\mathrm{C}_{6} \mathrm{H}_{3}$ & $\mathrm{C}_{6} \mathrm{H}_{3}$ & $2 g$ & & 72 \\
\hline
\end{tabular}

Table 1. 'H-NMR chemical shifts ( $\delta$ values) and coupling constants (absolute values, $\mathrm{Hz}$ ) of cis-3,3a,4,5,6,6a-hexahydro-4,5,6-methenocyclopentapyrazoles (2) in CDCl3. The multiplicities are given only for the parent compound ( $2 a)$ : they are observed only in a high-field spectrum, since at low field second order effects interfere. The following coupling constants are those of 2 aith the deviations in the 8 pectre

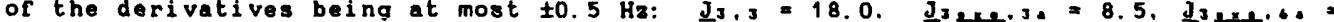

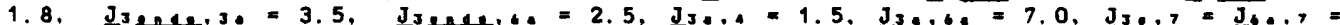

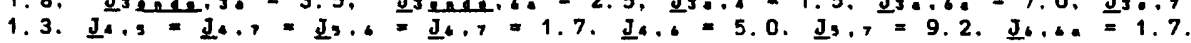

\begin{tabular}{|c|c|c|c|c|c|c|c|c|}
\hline compd & exo-3-H & endo-3-H & $3 a-H$ & $4-H$ & $5-\mathrm{H}$ & $7-\mathrm{H}$ & $6-H$ & $6 a-4$ \\
\hline $\begin{array}{l}2 a \\
2 b^{\circ} \\
2 a^{\circ} \\
2 d^{c}\end{array}$ & $\begin{array}{l}4.06 \\
\mathrm{ddd} \\
4.06 \\
-\end{array}$ & $\begin{array}{l}\text { 4. } 15 \\
\text { ddd } \\
4.23 \\
- \\
-\end{array}$ & \multicolumn{4}{|c|}{$\begin{array}{l}1.70-2.40 \\
1.70-2.40 \\
1.70-2.30\end{array}$} & $\begin{array}{r}2.79 \\
d q \\
2.78 \\
2.78 \\
2.73\end{array}$ & $\begin{array}{r}5.15 \\
\text { ddq } \\
5.20 \\
5.12 \\
5.12\end{array}$ \\
\hline $20^{\circ}$ & - & 5. 18 & & $0-2$ & & 1.93 & 2.85 & 5. 33 \\
\hline $2 \Gamma^{\circ}$ & ' & - & 2. 46 & 1. 30 & 1.93 & 1.71 & 2.85 & $i$ \\
\hline $20^{\circ}$ & - & - & 2. 93 & 1. 38 & 2. 00 & 1. 70 & 2. 87 & 5. 35 \\
\hline
\end{tabular}

$1.23\left(\mathrm{~d}, \underline{J}=7.3, \mathrm{CH}_{3}\right) .01 .52\left(\mathrm{~d}, \underline{\mathrm{J}}=7.5, \mathrm{CH}_{3}\right) .91 .10\left(\mathrm{~s}, \mathrm{exO}-\mathrm{CH}_{3}\right), 1.43(\mathrm{~s}$, endo- $\left.\mathrm{CH}_{3}\right)$. $7.00-7.30\left(\mathrm{~m}, \mathrm{C}_{6} \mathrm{H}_{5}\right) .6 .9-7.5\left(\mathrm{~m}, \mathrm{C}_{6} \mathrm{H}_{5}\right) .\left(4.9-5.4 .7 .30\left(\mathrm{~m}, 2 \mathrm{C}_{6} \mathrm{H}_{5}\right)\right.$.

Table 2. "3C-NMR chemical shifts ( $\delta$ values) and ${ }^{13} \mathrm{C}-\mathrm{H}$ coupling constants ( $\mathrm{Hz}$ ) of cis-3. 3a, 4, 5, 6, 6a-hexahydro-4, 5, 6-methenocyclopentapyrazoles (2). The 'Je.H values are given only for the parent compound ( $2 a)$ (second 1 ine) with the deviations in the spectra of the derivatives being at most \pm 3 Hz. Among the coupling constants across two or more bonds. the following are considered to be unambiguous: ${ }^{3} \mathrm{~J} e-4.6-n$

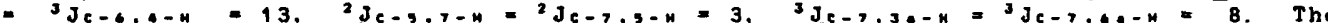
specific assignments are based on Je, patterns in the proton-coupled spectra.

\begin{tabular}{|c|c|c|c|c|c|c|c|}
\hline compd & $c-3$ & $c-3 a$ & $c-4$ & $c-5$ & $c-6$ & $c-6 a$ & $c-7$ \\
\hline $\begin{array}{l}2 a^{\circ} \\
2 b^{c} \cdots \\
2 a^{c} \cdots \\
2 d^{c} \cdots \\
2 a^{\circ} \cdots \\
2 c^{\cdots} \cdots \\
2 g^{c} \cdots\end{array}$ & $\begin{array}{l}77.5 \\
83.0 \\
80.2 \\
84.8 \\
93.3 \\
89.0 \\
97.8\end{array}$ & $\begin{array}{r}37.1 \\
141 \\
44.4 \\
39.0 \\
46.8 \\
47.0 \\
41.5 \\
46.4\end{array}$ & $\begin{array}{r}38.4 \\
170 \\
36.7 \\
32.8 \\
34.1 \\
38.2 \\
35.0 \\
36.0\end{array}$ & $\begin{array}{l}7.7 \\
216 \\
6.6 \\
5.8 \\
6.7 \\
8.0 \\
6.3 \\
6.3\end{array}$ & $\begin{array}{r}39.2 \\
170 \\
37.9 \\
37.9 \\
38.0 \\
39.0 \\
38.8 \\
38.2\end{array}$ & $\begin{array}{r}98.7 \\
150 \\
97.0 \\
97.8 \\
97.3 \\
100.0 \\
98.9 \\
99.3\end{array}$ & $\begin{array}{r}0.4 \\
218 \\
-0.4 \\
0.7 \\
1.1 \\
1.0 \\
2.1 \\
2.1\end{array}$ \\
\hline
\end{tabular}

- Solvent D. D.. P141 (ende-H). 139 (exo-H). Solvent CDCl3. 18.1 (CH3). 12.9 ( $\left.\mathrm{CH}_{3}\right)$. 20.9 (endo- $\left.\mathrm{CH}_{3}\right) .27 .6\left(\mathrm{exo}-\mathrm{CH}_{3}\right) .127 .5-128.9$ (o-C. m-C. p-C), 140.0 (ipso-

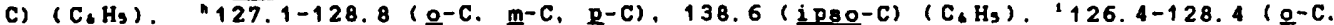

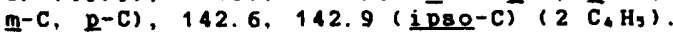


Ethyl diazoacetate did not react with benzvalene (1). However, methyl 2-diazopropionate and 1 afford both the stereoisomeric 1-pyrazolines. The results of the reactions of 1 with tetrachlorodiazocyclopentadiene, diazofluorene, and 5-diazo10,11-dihydro-5H-dibenzol a, dj cycloheptene will be described elsewhere."

With regard to the mechanism, the reaction of diazoalkanes with alkenes is one of the most thoroughly studied 1,3-dipolar cycloadditions. This is true for experimental as well as theoretical investigations. 0 . Therefore, it was of interest to determine the rate of the reaction between diazomethane and benzvalene (1) and to integrate 1 into the scale of dipolarophiles." Because of the simple experimental set-up, we have carried out competition experiments, in which 1 and norbornene, both in excess relative to the 1,3-dipole, competed for diazomethane and, in a second series, also for 2-diazopropane. The norbornene adduct 3 a of diazomethane ${ }^{\circ}$ and the rate constant for its formation are known. 10 The norbornene adduct $3 d$ of 2-diazopropane has now been obtained in 79x yield. In the experimental part, the data of the individual competition experiments are collected, from which the following ratios of the rate constants have been calculated according to ref. 41 .

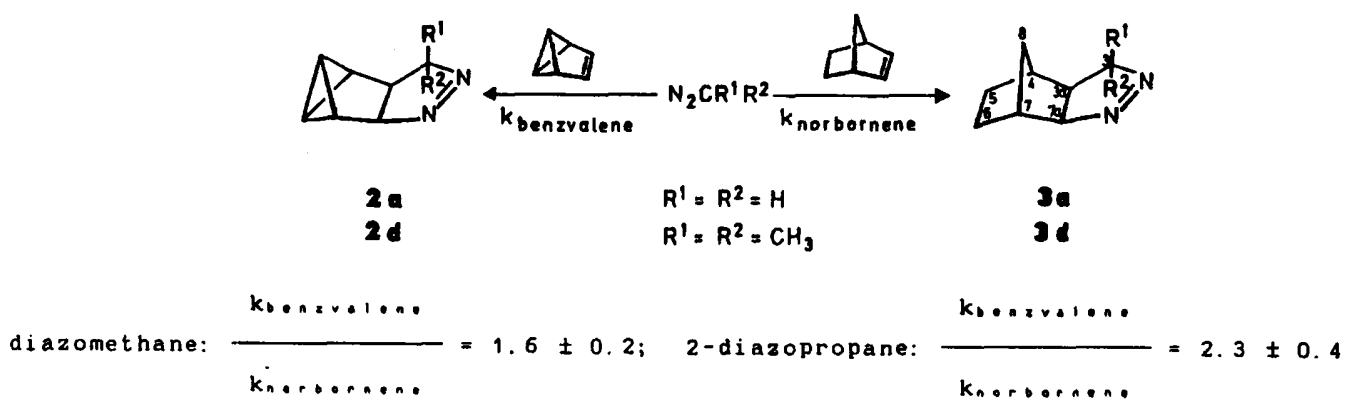

Thus, benzvalene (1) reacts somewhat faster than norbornene with both the diazoalkanes. However, the rate ratios are closely related to the competition constant with regard to benzonitrile oxide, which takes up these olefins equally fast." 2 The FMo-theory describes the cycloadditions of nitrile oxides with electron-rich olefins, in which category 1 and norbornene have to be included on the basis of the ionization potentials, 3 as controlled by the LuMo of the 1,3-dipole. 10. on the contrary, the control by the HOMO of diazomethane rationalizes the relative rates of the cycloadditions of this 1,3-dipole best. 10 . This should be valid to an even greater extent for 2-diazopropane. Since 1 has a lower ionization potential (corresponding to the $\pi$-orbital) and, most probably, a less accessible $\pi^{*}$-orbital than norbornene, we had expected that 1 would react slower than norbornene with these 1,3-dipoles. This is not the case, however. Obviously, the rates of these cycloadditions are not dominated by frontier orbital interactions, but by the relief of olerin strain."

Preparation of tetracyclof 4.1.0.02,4.03.3 jheptanes 4 from the 1-pyraxolines $2^{3}$ Heretofore, the exclusive route for the synthesis of the tetracyclol 4.1.0.$0^{2} \cdot .0^{3}, 3$ heptane system was the addition of halocarbenes to benzalene.13.1. The parent hydrocarbon 5a has been obtained by reduction of the 7,7-dibromo and 7,7dichloro derivatives." Another access to cyclopropane derivatives is provided by the nitrogen extrusion from 1-pyrazolines. 17. Thus, the 1-pyrazolines 2 offered the possibility to prepare 5 as well as derivatives thereof with methyl and phenyl groups in position 7. And indeed, the irradiation of $2 a-g$ in benzene through Pyrex glass afforded the tetracyoloheptanes la-g in $27-81 x$ yield. 


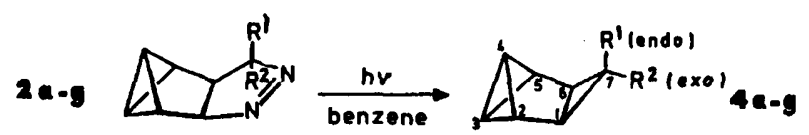

The new route to 4 a is 1088 efficient than the one published earlier, is but the derivatives ib-gare not available by any previous pathway. In the cases of the methyl pyrazolines $2 b, c$ and the phenyl pyrazoline $2 \mathrm{r}$, the nitrogen extrusion appears to proceed largely with retention, but the isomer ratios of the starting materials and of the products were not analyzed with sufficient accuracy to allow a more precise statement. Irradiation of pure 20 afforded pure 4 , however.

The NMR spectra of the hydrocarbons ( for ' $H-N M R$, see Table 3; for ${ }^{13} \mathrm{C}-\mathrm{NMR}^{3}$, see ref. 19) are characterized by large differences between the chemical shifts of the structurally related 3- and 4-CH groups ('H-NMR, 0.53-1.52 ppm; $13 \mathrm{C}-\mathrm{NKR}, 18.5-$ 26. $1 \mathrm{ppm}$. These differences originate from the orientation of the respective CH group relative to the anellated cyclopropane ring. The "H-NMR spectrum of $4 a^{1}$ and the "JC-NKR spectra of $4 a-g^{1}$ have been discussed in detail. Hithin the isomeric pairs $b, c$ and $40, f$, the stereochemical assignments are based on the ${ }^{3} \mathrm{C}$ chemical shifts', as well as on 'H-'H coupling constants, in particular on $3_{1}, 1$ eee 2.6 and $\mathrm{J}_{1}, \mathrm{Tex}=6.7 \mathrm{~Hz}$. Because of the endo phenyl group in 4f, g, 4-H experiences the anisotropy effect resulting in a remarkable upfield shift ( $\delta 0.93$ and 1.06 , respectively) of the signal relative to that of 4 ( $\delta 1.55)$.

Table 3. 'H-NMR chemical shifts ( $\delta$ values) and coupling constants (absolute values, $\mathrm{Hz}$ ) of tetracyclol 4.1.0.02, . $0^{3}, 3$ jeptanes (4) in CDCls. Average values of coupling

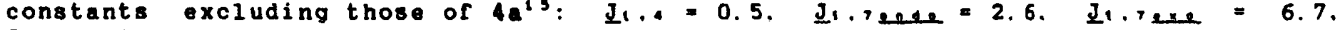
$\underline{J}_{2}, 3=1.0 \pm 0.2, \underline{J}_{2} .4=2.5 \pm 0.2, \underline{J}_{3}, 4=9.1 \pm 0.5 . \underline{J}_{3} .1 .2=1.1(50) .1 .6(5 \xi)$. J.. Tenes $=0.6$.

\begin{tabular}{|c|c|c|c|c|c|c|}
\hline compd & $1,6-\mathrm{H}$ & 2. $5-\mathrm{H}$ & $3-\mathrm{H}$ & $4-\mathrm{H}$ & $R^{1}($ endo $)$ & $R^{2}(e \times 0)$ \\
\hline $\begin{array}{l}40 \\
40^{\circ} \\
40^{\circ} \\
40 \\
40 \\
48\end{array}$ & $\begin{array}{l}1.07 \\
0.86 \\
1.19 \\
0.93 \\
1.34 \\
1.52 \\
1.92\end{array}$ & $\begin{array}{l}2.15 \\
2.16 \\
1.92 \\
1.92 \\
2.16 \\
1.85 \\
2.06\end{array}$ & $\begin{array}{l}2.29 \\
2.26 \\
2.47 \\
2.41 \\
2.26 \\
2.40 \\
2.58\end{array}$ & $\begin{array}{l}1.51 \\
1.56 \\
1.80 \\
1.88 \\
1.55 \\
0.93 \\
1.06\end{array}$ & $\begin{array}{l}0.57 \\
0.71 \\
1.27 \\
1.26 \\
1.93 \\
6.8-7.4\end{array}$ & $\begin{array}{l}0.50 \\
0.86 \\
0.83 \\
0.78 \\
6.8-7.3 \\
2.17 \\
5\end{array}$ \\
\hline
\end{tabular}

$\underline{J}, \mathrm{CHJ}=6.2$. $\underline{J}_{\mathrm{T}}, \mathrm{CHJ}=5.8$.

As reported for the parent hydrocarbon $4 a^{20}$, the derivatives $4 b-g$ rearrange on heating at temperatures above $160^{\circ} \mathrm{C}$ to bicyclol 3. 2.01hepta-2, 6-dienes and cycloheptatrienes. 2 Characteristically for bicyclol 1.1.03butane derivatives, $224 a-g$ are sensitive to acids, which undergo addition across a lateral bicyclobutane bond andor cause the conversion into the corresponding cycloheptatriene.2 such processes occur more easily the greater the strain in the respective compound. Thus, the endo-methyl (40) and endo-phenyl derivatives (4f) are transformed to 7-methyland 7-phenylcycloheptatriene, respectively, at $20^{\circ} \mathrm{C}$ in deuteriochlorororm within several days, whereas the stereoisomers tb and te survive under these conditions.

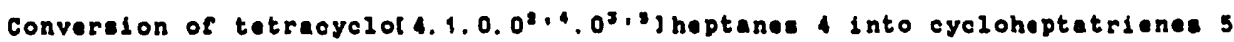

Many polycyclic hydrocarbons are subject to isomerization on treatment with catalytic quantities of silver ions. ${ }^{23}$ This reagent transforms the majority of bicyclof 1.1.01butane derivatives to 1,3-butadienes. 22.23 He have shown that silver salt catalysig gives rise to the formation of 1,3-cyclohexadiene from tricyclo[3.1.0. $0^{2} \cdot{ }^{\circ}$ ) hexane ${ }^{2}$ and of cycloheptatriene sa from tetracycloheptane ta with the latter process being highly exothermic. 's This reaction has been utilized to prepare 3,4-dideuteriocycloheptatriene free of isotopomers." We describe now the application of this method to the tetracycloheptanes $4 b-g$. 


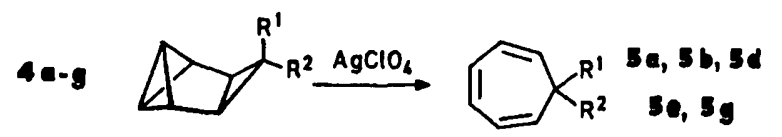

On treatment with silver perchlorate in benzene, with a catalytic quantity being sufficient in three out of four cases, ab-g rearranged in high yield to $7-$ methyl-(5b), 7,7-dimethyl- (5d), 7-phenyl- (5e), and 7,7-diphenylcycloheptatriene (5g), respectively. As to the mechanism of these processes, we refer to the speculations advanced in connection with the conversion of 40 into $5 a . "$ "

For the synthesis of 7-methyl-(5b) and 7-phenylcycloheptatriene (5e), the above method provides no progress since these compounds can be expeditiously prepared from the tropylium ion and the corresponding Grignard reagent. 1 However, 7, 7dimethyl- (5d) and 7,7-diphenylcycloheptatriene (5g) are made more readily accessible than before by the reaction sequence described herein. In both cases, the overall yield for the three steps frombenzvalene (1) is $40-45 \%$ and for the four steps from cyclopentadiene 17 - 20x. Or course, the diazoalkanes have to be provided requiring two or three steps, but very simple ones. Hoffmann and Frickel ${ }^{2}$ obtained 5d in 17x yield in three steps starting from 1,2,3,4-tetrachloro-5,5dimethoxycyclopentadiene and 3,3-dimethylcyclopropene with three additional steps necessary for the synthesis of the latter educt. Because of the simultaneous formation of $\alpha$-methylstyrene, the route to $5 d$ from methyl 7-methylcycloheptatriene-7carboxylate is even less efficient. The direct pathway from benzene and diphenyldiazomethane to $5 \mathrm{~g}$ affords a yield of only $8 \%$ after elaborate chromatographic separation. "For the preparation of synthetically useful quantities of 50 , our procedure utilizing benzvalene (1) as benzene equivalent certainly has its merits. Doubtless many other cycloheptatrienes with alkyl and aryl substituents in the $7-$ position should be conveniently accessible by means of this methodology.

The cycloheptatrienes $5 b, d, e, g$ have been characterized by their NMR spectra (see Table 4 for the 'JC-NKR chemical shifts of $5 d, \bullet, g$ ). Here we noticed that $1,6-H$ of the diphenyl derivative $5 g$ resonate substantially more upfield $(\delta$ 4.65) than 1,6-H of the monophenyl compound 5e $(\delta 5.42)$. Additionally, the signal of $c-1,6$ of 5o appears at much higher field $(\delta 95.6)$ than the corresponding line of se $(\delta$ 126. 2). These phenomena indicate that $\mathrm{gg}$ is not a single substance but an equilibrium mixture of the cycloheptatriene (5gc) and the norcaradiene form ( $5 \mathrm{gN}$ ). On the basis of these chemical shifts, Hannemann has estimated the ratio $50 \mathrm{c}: 5 \mathrm{gN}$ to be about 65 : 35 at ambient temperature. Ne recorded the ${ }^{13} \mathrm{C}-\mathrm{NMR}$ spectrum of 50 at lower temperatures too and observed that the signal of $c-1,6$ moved from $\delta 95.6$ at $314 \mathrm{~K}$ to 82.6 at $183 \mathrm{k}$. Due to extensive broadening, this absorption disappeared in the noise at $163 \mathrm{k}$. Hith our instrument we were unable to reach a temperature sufficiently low to freeze the equilibrium $5 g c \Rightarrow$ gol and so provide the individual resonances of both forms.

Table 4. "J C-NMR chemical shifts ( $\delta$ values) of some cycloheptatrienes 5

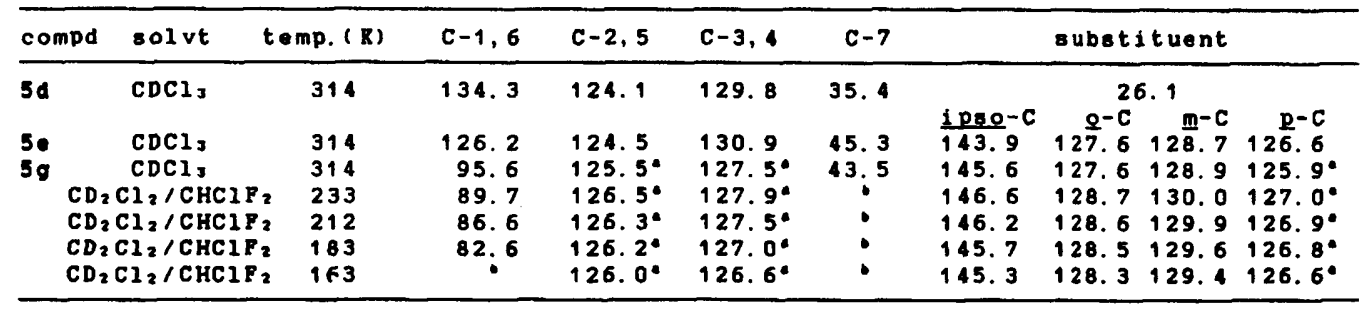

The assignment of $c-2,5, c-3,4$, and $p-c$ is only tentative. Not observed due to low intensity because of broadening. 


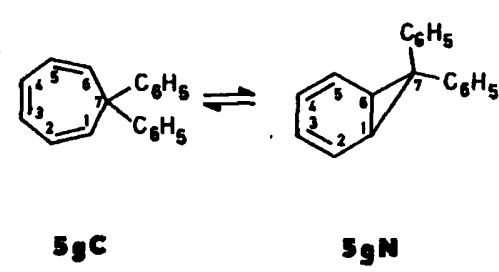

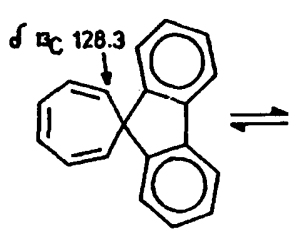

oc

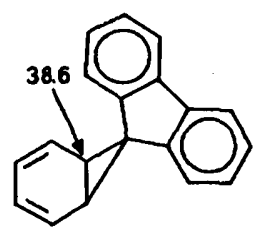

$6 N$

To calculate the exact ratio $5 \mathrm{gc}$ : $5 \mathrm{gH}$, the individual chemical shifts are necessary, however. Accordingly, we have estimated these with the aid of the corresponding values for the spiro compounds $6 \mathrm{C}$ and $6 \mathrm{~K}$, the individual chemical shifts of which have been determined by Durr and Rober. ${ }^{2}$ The compounds 6 as well as 59 carry two phenyl groups in position 7 though these are directly connected to each other via the ortho-positions in 6. To a first approximation, we assume that the 7substituents or $5 g$ and 6 exert equal effects on the ${ }^{13} \mathrm{C}-N M R$ chemical shifts of the ring carbon atoms. By transfer of the $\mathrm{C}-1,6$ values of $6 C(\delta 128.3)$ and 8 ( $(\delta 36.8)$ to $5 g C$ and $5 g N$, respectively, we have calculated the ratio $5 g C: 5 g N$ for those temperatures at which the C-1,6 signal was observed: $314 \mathrm{R}, 63: 37 ; 233 \mathrm{R}, 56$ : 44; $212 \mathrm{~K}, 53: 47 ; 183 \mathrm{~K}, 49: 51$. Prom the temperature dependence of these ratios we have obtained the enthalpy and the entropy for the conversion $5 g C \rightarrow 5 g k: \Delta H a=$ $-530 \mathrm{cal} / \mathrm{mol}, \mathrm{SSh}_{\mathrm{N}}=-3 \mathrm{eu}$. Because of the above-mentioned assumption, these values are only rough estimates. The greater temperature dependence of the ratio 6C: $6 \mathrm{~N}$ $(290 \mathrm{R}, 78: 22 ; 160 \mathrm{R}, 49: 51)$ indicates a larger negative enthalpy as well as a larger negative entropy of reaction for the process $6 \mathrm{C} \rightarrow 6 \mathrm{~N}$. In spite of that. the ratios 5gC: $5 \mathrm{gN}$ and $6 \mathrm{C}$ : $6 \mathrm{~N}$ appear astoundingly similar in view of the different orientation of the phenyl groups in these systems. Being arranged in a bisected manner, the $\pi$ orbitals of the fluorene moiety in $6 \mathrm{~N}$ interact optimally with the cyclopropane walsh orbitals thus exerting the maximum acceptor ability of the aromatic unit. Good $\pi$ acceptors in the 7-position are one of the requisites for a high norcaradiene share in a cycloheptatriene/norcaradiene equilibrium. ${ }^{20}$ However, in $5 \mathrm{gN}$ both the phenyl groups should be twisted relative to the bisected conformation by about $90^{\circ}$ due to mutual steric hindrance. Thus, an interaction of the $\pi$ orbitals and the cyclopropane Halsh orbitals cannot be operative. Nevertheless, the proportion of $5 \mathrm{gN}$ in the $5 \mathrm{gc} / 5 \mathrm{gN}$ mixture is rather high. The fact that the introduction of a methyl group in one ortho-position of one phenyl group of $5 g$ causes the equilibrium to shift virtually completely to the side of the norcaradiene' indicates the relative unimportance of electronic effects and the dominance of steric effects ${ }^{2}$ in these systems.

Heat of formation of tetracyclol 4.1.0.02. $.0^{3}, 3$ jheptane (4a)

The strong exothermicity and the high yield of the silver ion catalized rearrangement 4 a $\rightarrow$ a offered the posibility to determine the enthalpy of reaction, from which the heat of formation of 4 a can be derived. The measurements have been conducted in toluene as solvent by isothermal titration-calorimetry. The calorimeter, experimental method, accuracy of measurements have already been reported. 2

Cycloheptatriene ( 5 a) forms a complex with AgBf, used to effect the rearrangement of 4a. To calculate $\Delta H_{k}$ of $4 a \rightarrow$ se the corresponding heat of complexation has to be accounted for. It was determined in analogy to $\Delta H_{n}$ of $4 a \rightarrow 5 a$ by titration of a toluene solution of $3 a$ to the stock or AgBF..

For an accurate calculation of the heat of reaction a correction for the difference in enthalpies of solution and evaporation of educts and products has to be made. As has been shown previously, these differences generally are small for isomers. ${ }^{2}$ The heat of solution difference in isooctane can be estimated by a 
"double-bond increment" of 0.1 kcal/mol per double bond. 2 "To test whether this relation is valid also in toluene, the solvent used in this study, first heats of solution of $5 \mathrm{a}$ and cycloheptane in toluene were measured by using the method described earlier. ${ }^{2}$. The values of $\Delta \mathrm{H}$ = 0.06 and $0.58 \mathrm{kcal} / \mathrm{mol}$ indicate that within the accuracy of the method ( $\left.\neq 0.1 \mathrm{kcal} / \mathrm{mol}^{2 *}\right)$ the increment approach can also be applied to toluene solutions.

With the data given in Table 7 (see experimental part) and the known heat of formation of $5 a^{30}$ the heat of formation of $4 a$ is obtained by:

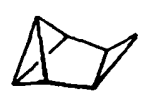

$4 a$

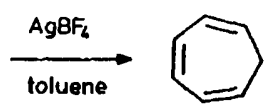

$5 \mathbf{a}$ heat of rearrangement

corr. for complex formation of 5 a

corr. $\triangle \Delta H_{L}$

$\triangle H P$ of 5 a
$+46,3 \mathrm{kcal} / \mathrm{mol}$

-2. $2 \mathrm{kcal} / \mathrm{mol}$

-0. $3 \mathrm{kcal} / \mathrm{mol}$ $+44.6 \mathrm{kcal} / \mathrm{mol}$

$\Delta H^{\circ}$ of $4 a$

88. $4 \mathrm{kcal} / \mathrm{mol}$

Derived from this value and $\Delta H 9$ of strain free $4 a$, which is obtained by using group increments, ${ }^{\prime \prime}$ the strain energy of $4 a$ can be calculated. In Table 5 , this value ( $\Delta H_{1}$ ) is compared to the strain energy of bicyclol 1.1.0lbutane, benzalene (1), and tricyclol 4.1.0.02,7 heptane.

Table 5. Strain energies ( $k$ cal/mol) of several bicyclol 1.1.0 butane derivatives

\begin{tabular}{|c|c|c|c|c|}
\hline$\Delta H ?$ & $51 \cdot 9^{32}$ & $87 \cdot 3^{33}$ & 88.4 & $44.6^{34}$ \\
\hline$\Delta H_{1}$ & 65.5 & 77.7 & 104.7 & 67.0 \\
\hline
\end{tabular}

\section{EXPBRI MBNTAL}

General and inetrumentation. See ref. 35 .

Addition of diezoalkanes to benzvalene (1) - preparation of elg-3, 3a,4,5,6,6a-hexahydro-4,5, 6-methenocyclopentepyrazole: (2)

Parent compound ( $2 \mathrm{a})$ : A mixture of 408 aqueous KOH $(25 \mathrm{ml})$ and ether (20 ml) containing benzvalene (1) $36(780 \mathrm{mg}, 10.0 \mathrm{mmol})$ was cooled to -5 c 1 , treated with 1-methyl-1-nitrosourea 7 ( $10.0 \mathrm{~g}, 97.1 \mathrm{mmol})$ in a manner that the temperature did not rise above $0{ }^{\circ} \mathrm{C}$ and, thereafter, stirred at $-5{ }^{\circ} \mathrm{C}$ for $30 \mathrm{~min}$. The layers were separated, and the yellow ether layer was set aside in a dark place at 20 . $c$ until the color had disappeared (several days). Concentration in vacuo and distillation of the residue at $55-60^{\circ} \mathrm{C}$ (bath)/0.1 Torr afforded $1.00 \mathrm{~g}(83 \times)$ of $2 a$ as a colorless liquid. IR ( film) $1548(\mathrm{~N}=\mathrm{N}) \mathrm{cm}^{-1}$. UV (cyclohexane) $\lambda_{\text {. }} \times(\varepsilon) 330(280) \mathrm{nm}$. $1 \mathrm{H}-$ NMR, see Table 1. ${ }^{3} \mathrm{C}-\mathrm{N} M R$, see Table 2. (Found: C, 69.75; H, 6.72; N, 23.47 . Calc for $\mathrm{C}_{7} \mathrm{H}_{0} \mathrm{~N}_{2}(120.2)$ : C, 69.97; H, 6.71; N, 23.32\%.)

exo- (2b) and endo-3-Methyl (2c) derivatives: The reaction of 1 and diazoethane ( from 1-ethyl-1-nitrosoureaj) was carried out as above. The orange-yellow color or the ether layer had disappeared after 15 h at $20^{\circ} \mathrm{C}$ in the dark. Distillation at 40-50 C (bath)/0.001 Torr afforded a colorless oil (58\%), which contained mainly $2 b$ and 20 in the ratio 1.7 : 1.0. An analytically pure sample (31x yield) consisting of $2 b$ and $2 c$ in the ratio $3.0: 1.0$ was obtained by chromatography (SiOz, 3 :

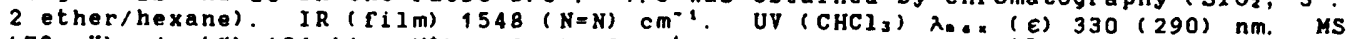
$(70 \mathrm{eV}) \mathrm{m} / \mathrm{z}(\mathrm{x}) 134\left(1, \mathrm{H}^{*}\right), 91(100)$. 'H-NMR, see Table 1. " $\mathrm{H}$-NMR, see Table 2. (Found: C, 71.68; H, 7.45; N, 20.66. Calc for CaH O ONz (134.2): C, 71.61; H, 7.51;

3, 3-Dimethyl derivative (2d): According to ref. 39, 2-diazopropane was prepared from acetone hydrazone. Thus, mercuric oxide (60.0 g, $270 \mathrm{mmol}), 3 \mathrm{H}$ R in ethanol $(4.5 \mathrm{ml})$, and ether $(60 \mathrm{ml})$ were placed under nitrogen in three-necked flask equipped with a dropping funnel and a manetic stirrer. externalyvanind 
water bath $\left(20^{\circ} \mathrm{C}\right)$. The flask was connected to a trap containing $1(1.009$, 12.8 mmol) in ether $(25 \mathrm{ml})$, which was cooled to $-80^{\circ} \mathrm{C}$. This trap was connected to an empty trap cooled with liquid nitrogen. Via the two traps, the pressure in the apparatus was reduced to about 200 Torr, and acetone hydrazone (15.0 g, $210 \mathrm{mmol})$ was added dropwise to the vigorously stirred mixture within 20 min. Hith continued stirring, the pressure was then reduced to 15 Torr for 10 min. Thereafter, the traps were allowed to warm to $20^{\circ} \mathrm{C}$ under normal pressure. Their contents (red solutions) were combined and set aside in a dark place at 20 ' $C$ for $15 \mathrm{~h}$. Concentration in vacuo and distillation of the residue at 60 " $\mathrm{C}$ (bath)/0.001 Torr gave 1.90 g of rather pure $2 \mathrm{~d}$ as a colorless oil, which rapidly solidified. Chromatography (SiO.2, ether/hexane) and a second distillation furnished 1.76 g (93x) of analyti-

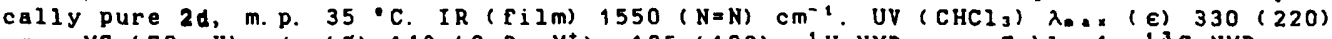
$\mathrm{nm}$. MS $(70 \mathrm{eV}) \mathrm{m} / \mathrm{z}(\mathrm{X}) 148\left(0.2, \mathrm{M}^{+}\right), 105(100)$. 'H-NMR, see Table 1. 13 C-NMR, see Table 2. (Found: C, 73.15; H, 7.98; N, 18.85. Calc for $\mathrm{C}_{9} \mathrm{H}_{22} \mathrm{~N}_{2}(148.2):$ C, 72.94; H, 8. 16; N, 18.90\%.)

exo- (20) and endo-3-Phenyl (2f) derivatives: Phenyldiazomethane ${ }^{0}(3.00$ g, 25.4 mmol) was dissolved in ether $(75 \mathrm{ml})$ containing $1(1.98 \mathrm{~g} 25.4 \mathrm{mmol})$ After 5 d at $20{ }^{\circ} \mathrm{C}$ in the dark, the mixture was concentrated in vacuo and the residue distilled at 110-120 " C (bath)/0.001 Torr to give a brownish oil, which solidified on standing and consisted of 20 and $2 f$ in the ratio of about $1.5: 1.0(73 x)$ and some benzaldehyde azine. Chromatography ( $\mathrm{SiO}_{2}, 12$ : 1 cyclohexane/ethyl acetate) afforded a brownish solid. Distillation as above and recrystallization from n-hexane provided $2.18 \mathrm{~g}(44 \%)$ or 2 as a colorless solid, m. p. 94-95 C C. The ende-isomer $2 f$ could not be recovered from chromatography. Analytical data for $20: \frac{1 R}{\text { (RBr) } 1534}$ $(\mathrm{N}=\mathrm{N}) \mathrm{cm}^{-1}$. UV $\left(\mathrm{CHCl}_{3}\right) \lambda_{\ldots} \ldots(E) 260(\mathrm{sh} 630), 267(\mathrm{sh} 400), 283(240), 296(230)$, $332(300) \mathrm{nm}$. MS $(70 \mathrm{eV}) \mathrm{m} / \mathrm{z}(X) 196\left(2, M^{*}\right), 167(100)$. (Found: C, 79.64; H, 6. 32; $\mathrm{N}$, 14.19. Calc for $\mathrm{C}_{1} 3 \mathrm{H}_{12} \mathrm{~N}_{2}(196.3):$ C, 79.56; H, 6.16; N, 14.28\%.) NMR-spectra of 2. and $2 C$, see Tables 1 and 2 .

3,3-Diphenyl derivative (2g): Diphenyldiazomethane's $(1.00 \mathrm{~g}, 5.15$ mmol) was stirred in ether $(15 \mathrm{ml})$ containing,$(400 \mathrm{mg}, 5.12 \mathrm{mmol})$ at 20 . C in the dark for 8 d. Brownish crystals precipitated from the red solution. The mother liquor was concentrated in vacuo to give a solid residue. The combined products were washed with cold hexane and proved to be rather pure $2 g(1.009,72 \%)$. Recrystallization from dichloromethane/n-hexane gave colorless crystals, m. p. 152 . C. IR (KBr) 1582 $(\mathrm{C}=\mathrm{C}), 1544(\mathrm{~N}=\mathrm{N}) \mathrm{cm}^{-1}$. UV (ethanol) $\lambda_{*} \ldots(\varepsilon) 220(\mathrm{sh} 510), 241(2430), 260(910)$, $266(780), \quad 273(\mathrm{sh} 470), \quad 336(310) \mathrm{nm}$. MS $(70 \mathrm{eV}) \mathrm{m} / \mathrm{z}(\%) 245(14), 244(23), 165$ $(100)$. 'H-NMR, see Table 1. I3 C-NMR, see Table 2. (Found: C, 83.81; H, 5.64; N, 10.57. Calc for $\mathrm{C}_{1}, \mathrm{H}_{1}, \mathrm{~N}_{2}(272.4): \mathrm{C}, 83.79 ; \mathrm{H}, 5.92 ; \mathrm{N}, 10.29 \%$ )

Competition of benzvalene (1) and norbornene for diazomethane and 2-diazopropane: Solutions of the diazoalkanes in ether were prepared according to refs. 37 , 39 and their concentrations determined by reaction with an excess of benzoic acid and titration of the remaining benzoic acid with $0.1 \mathrm{~N} \mathrm{NaOH}$. The diazoalkane solutions were mixed with solutions of 1 and norbornene of known concentrations and set aside in a dark place at $20^{\circ} \mathrm{C}$ over night. The ether was evaporated in vacuo and the residues were distilled as described for the isolation of 2 a and $2 d$ to give pure mixtures of $2 a, 3 a$ and $2 d, 3 d$, respectively. The ratios of the products were determined by integration of the ' H-NMR signals of $2 a$ at $\delta 4.70$, of $3 a$ at 3 . $90-$ 4. 30, of 26 at 5.12, and of 3d at 4.62. Pyrazoline 3a is a known compound ${ }^{10}$ and its 3,3-dimethyl derivative 3d is described below. The ratios of the rate constants $k_{0} \ldots v_{1 \ldots}$ : $k_{n} \ldots \ldots \ldots \ldots n$. ( $\left.k_{0}: k_{n}\right)$ were calculated according to rer. 11. In Table 6 the data of the individual experiments are collected.

Table 6. Competition reactions of benzvalene (1) and norbornene with diazomethane and 2-diazopropane

\begin{tabular}{|c|c|c|c|c|c|c|c|}
\hline $\begin{array}{l}\text { experi- } \\
\text { ment }\end{array}$ & $\begin{array}{l}\text { mmol } \\
\text { diazo- } \\
\text { ethane }\end{array}$ & $\begin{array}{c}\text { mmol } \\
\text { benzva- } \\
\text { lene (1) }\end{array}$ & $\begin{array}{l}\text { mmol } \\
\text { norbor- } \\
\text { nene }\end{array}$ & $\underset{2 a}{\operatorname{mmol}}$ & $\underset{3}{\mathrm{mmol}}$ & $\begin{array}{l}\text { ratio } \\
k_{*}: k_{n}\end{array}$ & $\begin{array}{l}\text { combined } \\
\text { yield ( } x) \\
\text { of adducts }\end{array}$ \\
\hline 1 & 8. 40 & 15.2 & 16.0 & 4. 06 & 2.66 & 1.71 & 80 \\
\hline 2 & 2. 84 & 10.1 & 13.1 & 1.06 & 0.95 & 1.46 & 71 \\
\hline 3 & 2. 92 & 10.1 & 14.0 & 1. 34 & 1. 32 & 1.45 & 90 \\
\hline 4 & 5. 68 & 6.9 & 32. 4 & 1. 20 & 3. 34 & 1.75 & 80 \\
\hline \multirow[t]{2}{*}{5} & 7.05 & 6.9 & 35.3 & 1. 37 & 4. 27 & 1.72 & 80 \\
\hline & $\begin{array}{l}\text { 2-diazo- } \\
\text { propane }\end{array}$ & & & $2 d$ & $3 d$ & & \\
\hline 6 & 4. 20 & 7.7 & 4. 9 & 2. 55 & 0.91 & 1. 95 & 83 \\
\hline 7 & 7. 16 & 8.0 & 5.1 & 4. 25 & 1.49 & 2. 21 & 80 \\
\hline 8 & 5.97 & 5.4 & 18.2 & 1.96 & 2. 81 & 2.66 & 80 \\
\hline
\end{tabular}

$(3 a \alpha, 4 B, 7 B, 7 a \alpha)-3 a, 4,5,6,7,7 a-H e x a h y d r o-3,3-d i m e t h y l-4,7$-methano-3H-benzol c) pyrazole (3d): The preparation from 2-diazopropane and norbornene was carried ous according to the procedure for dimethylpyrazoline 2d: $79 x$ yield of 3d as colorless 


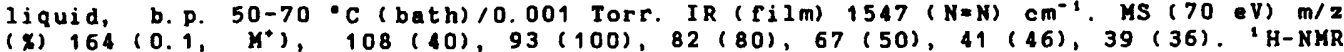

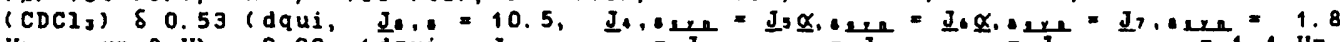

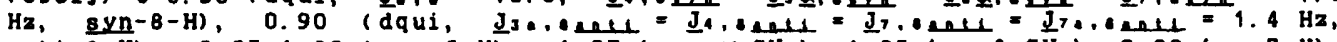
ant $i-8-H), 0.95-1.80(\mathrm{~m}, 6 \mathrm{H}), 1.07\left(\mathrm{~s}, \underline{\alpha-C H_{3}}\right), 1.35\left(8, \underline{\beta}-\mathrm{CH}_{3}\right), 2.00(\mathrm{~m}, 7-\mathrm{H})$, $2.77(\mathrm{~m}, 3 \mathrm{a}-\mathrm{H}), 4.62\left(\mathrm{dt}, \mathrm{J}_{3}, \mathrm{~T}=6.6, \mathrm{~J}_{7}, \mathrm{la}=1.4 \mathrm{~Hz}, 7 \mathrm{a}-\mathrm{H}\right)$.

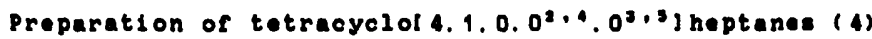

General procedure: A 1-pyrazoline 2 (5.03-22.9 mmol) was dissolved in anhydrous benzene $(50 \mathrm{ml})$. The solution was deoxygenated by a gentle stream of nitrogen for 15 min, and then irradiated (mercury vapor lamp, Hanau TQ 718) at 15 . C through Pyrex glass until the generation of nitrogen ceased $(2-4 \mathrm{~h})$. Therearter, the solvent was removed at 15 Torr $(40-g)$ or at 200 Torr through a 2 m spinning band column (4a-d). Further work-up was effected as described in the individual procedures.

Parent compound (4a): Distillation through a $2 \mathrm{~m}$ spinning band column at $30-$ 40 C (bath)/100 Torr afforded a fraction containing 21x 4a (27x yield) and 79x benzene. Compound a was identified by it "H-NMR spectrum."

exo- (4b) and endo-7-Methyl (4c) derivatives: $A 2.7: 1.0 \mathrm{mixture}$ of $2 \mathrm{~b}$ and 20 was photolyzed. Distillation of the crude product through an effective column (Fischer spaltrohr O, $20 \mathrm{~cm}$ ) provided a $47 \%$ yield of $4 \mathrm{~b}$ and $4 \mathrm{c}$ in the ratio 3.2 : 1.0 as colorless liquid, b. p. 63-65 $\mathrm{C} / 95$ Torr. MS $(70 \mathrm{eV}) \mathrm{m} / 2(x) 106\left(19, \mathrm{M}^{+}\right), 91$ $(100)$. H-NMR, see Table 3. '3 C-NMR, see ref. 19. (Found: C, 90.07; H, 9.56. CalC for $C_{0} H_{1} O(106.2):$ C, 90.51; H, 9. 49\%.)

7,7-Dimethyl derivative (4d): Distillation of the crude product through an effective column (Fischer spaltrohr $\theta, 20 \mathrm{~cm}$ ) provided a $46 \%$ yield of id as colorless liquid, b. p. $75-80^{\circ} \mathrm{C} / 90$ Torr. MS $(70 \mathrm{eV}) \mathrm{m} / \mathrm{z}(\mathrm{x}) 120\left(15, \mathrm{M}^{+}\right), 105(100)$. $1 \mathrm{H}-$ NMR, see Table 3. IJ C-NMR, se ref. 19. (Found: C, 89.33; H, 10.34. Calc for C, His $(120.2):$ C, $89.94 ; H, 10.06 \%$.)

exo- (4e) and endo-7-Phenyl (4f) derivatives: A 1,5 : 1.0 mixture of 20 and 25 containing some benzaldehyde azine was photolyzed. Distillation of the crude product at $40-70^{\circ} \mathrm{C}$ (bath)/0.01 Torr afforded an $81 \times$ yield of 40 and if in the ratio 2.4: 1.0 as colorless oil. IR (film) 1601 ( C=C) $\mathrm{cm}^{-1}$. MS $(70 \mathrm{eV}) \mathrm{m} / \mathrm{z}(\mathrm{x}) \mathrm{l68}$ $\left(83, M^{*}\right), \quad 167(100), 165(47), 153(26), 152(37), 91(20)$. 'H-NKR, see Table 3 IJ C-NMR, see ref. 19. (Found: C, 92.24; $H, 7.17$. Cale for $\mathrm{C}_{13} \mathrm{H}_{12}(168,2): \mathrm{C}, 92,81$; H, 7.19x.) Pure 4e (colorless oil) was obtained analogously from pure 2e in $73 \%$ yield.

7,7-Diphenyl derivative(4g): Sublimation of crude product at $80 \cdot \mathrm{C}(\mathrm{bath}) / 0.001$ Torr furnished a $78 \%$ yjeld of 40 s sightly yellow crystals, m, 73-75. C. IR $(\mathrm{KBr}): \quad 1594(\mathrm{C}=\mathrm{C}) \mathrm{cm}^{-1}$. MS $(70 \mathrm{eV}) \mathrm{m} / \mathrm{z}(\mathrm{x}) 244\left(53, \mathrm{M}^{+}\right), 243(25), 167(47), 166$

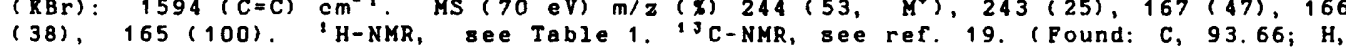
6.82. Calc for $\mathrm{C}_{1}, \mathrm{H}_{1}$, $(244.3): \mathrm{C}, 93.40 ; \mathrm{H}, 6.60 \%$.)

\section{Preparation of cycloheptatrienes (5)}

7-Methyl-1,3,5-cycloheptatriene (5b): A mixture of 4b,c (50 mg) dissolved in CDCls $(1 \mathrm{ml})$ was cooled to $0 \cdot \mathrm{C}$ and treated with 0.2 M anhydrous $A g C l 04$ in benzene ( 1 drop). A strong exothermicity was observed, and the ${ }^{2} H$-NMR spectrum showed that $5 b$ had been formed exclusively. The NMR spectra of $5 b$ have been described: "H-NMR, see ref. 42 ; I3 C-NMR, see ref. 43.

7,7-Dimethyl-1,3,5-cycloheptatriene (5d): The same procedure as described above for 5b was used to prepare $5 d$ from 4d. Larger quantities of $5 d$ required for reaction with singlet oxygen, were isolated by distillation. The solvent was removed through column at about 100 Torr and $5 d$ was obtained by distillation of the residue through an effective column (Fischer spaltrohr $0,20 \mathrm{~cm}$ ) at about 15 Torr. ' $\mathrm{H}$-NMR $\left(\mathrm{CDCl}_{3}\right) \delta 1.00\left(\mathrm{~s}, \mathrm{CH}_{3}\right), 5.15\left(\mathrm{~d}_{1} \underline{J}_{1,2}=9.6 \mathrm{~Hz}, 1-\mathrm{H}\right), 6.05(\mathrm{~m}, 2-\mathrm{H}), 6.43$ $(\mathrm{m}, 3-H)$, see also refs. 2, 3. I $\mathrm{C}-\mathrm{NMR}$, see Table 4.

7-Phenyl-1,3,5-cycloheptatriene (50): A mixture of $10, f(50 \mathrm{mg})$ dissolved in

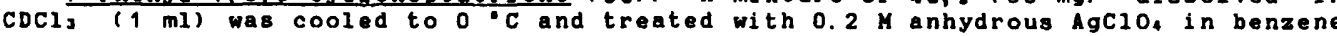
(1 drop). A strong exothermicity was observed. After $10 \mathrm{~min}$, the solution was concentrated in vacuo, and $40 \mathrm{mg}(80 \%)$ of pure 50 distilled from the residue at 25 'c (bath)/0.001 Torr as a colorless liquid, which crystallized, m. p. 28-30・c (30-31.5 (C4). H-NMR, see ref. 42 . I3 C-NMR, see Table 4.

2,7-Diphenyl-1,3,5-cycloheptatriene (5g): A solution of $\mathrm{g}(250 \mathrm{mg}, 1.02 \mathrm{mmol})$ in benzene ( $3 \mathrm{ml}$ ) was mixed with 0.2 M anhydrous AgClOa in benzene (3) ml) and stirred at 20 'C in the dark for $20 \mathrm{~h}$. After addition of dichloromethene $(20$ ml), the mixture was extracted three times with 15\% aqueous ammonia (15 ml each) and three times with water $(15 \mathrm{ml} e \mathrm{ch})$. The organic phase was dried with Nasso. and 
concentrated in vacuo to give $230 \mathrm{mg}$ of yellow crystals. Dissolution in the minimum possible volume of ether and cooling to $-30 \cdot \mathrm{C}$ gave $200 \mathrm{mg}(80 \%)$ of $5 \mathrm{~g}$ colorless crystals, m. p. 105-106 C. H. P., NHR-8pectra and MS are in accord with the dat reported earlier." IR (RBr) 3060, 3040, 3018, 1600, 1493, 1446, 1039, 762, 752, 745, 727, 600, $687 \mathrm{~cm}^{-1}$. UV $\left(\mathrm{CHCl}_{3}\right) \lambda_{1}$ ( $) 254(\mathrm{sh} \mathrm{6600),} 262(\mathrm{sh} 6000), 270(\mathrm{sh}$ $5300), \quad 282(\mathrm{sh} \mathrm{4200),} 302(8 \mathrm{~h} \mathrm{2600)}$. 'H-NAR (CDCls) $\delta 4.65(\mathrm{~m}, 1,6-\mathrm{H}), 6.06$ and 6.29 (each m, 2,5-H and $3,4-H), 7.0-7.3\left(\mathrm{~m}, 2 \mathrm{C}_{6} \mathrm{H}_{3}\right)$. ${ }^{13} \mathrm{C}-\mathrm{N} M R$, see Table 4. (Found: C, 93.32; H, 6.64. Calc for $C_{1}, H_{1}$. $(244.3): C, 93.40 ; H, 6.60$ )

Heat of reaction of the rearrangement $4 a \rightarrow 5 a$

By using the experimental set-up described previously"2, the toluene solution of 4. was titrated to a $0.046 \mathrm{M}$ solution of AgBF, in toluene. Experimental data are given in Table 7 .

Table 7. Heat of reaction of the rearrangement a $\rightarrow 5$ and heat of complexation of 5. with AgBF.

\begin{tabular}{|c|c|c|c|c|}
\hline substrate & $\begin{array}{l}\text { titration } \\
\left.\text { [10 } 10^{7} \mathrm{~mol} / \mathrm{s}\right]\end{array}$ & $\begin{array}{l}\text { energy } \\
\text { (meal/s) }\end{array}$ & $\begin{array}{c}-\Delta H^{\alpha} \\
[\mathrm{kca}] / \mathrm{mol}]\end{array}$ & \\
\hline $\begin{array}{l}4 a \\
4 a \\
4 a \\
4 a\end{array}$ & $\begin{array}{l}1.042 \\
1.063 \\
1.063 \\
0.946 \\
0.946\end{array}$ & $\begin{array}{l}4.7839 \\
4.8319 \\
4.8291 \\
4.2899 \\
4.3110\end{array}$ & $\begin{array}{l}46.47^{\circ} \\
46.18^{\circ} \\
46.16^{\circ} \\
46.10^{\circ} \\
46.34^{\circ}\end{array}$ & $46.3 \pm 0.1$ \\
\hline $\begin{array}{l}5 a \\
5 a\end{array}$ & $\begin{array}{l}1.080 \\
1.080\end{array}$ & $\begin{array}{l}0.2386 \\
0.2350\end{array}$ & $\begin{array}{l}2.21 \\
2.17 \\
\end{array}$ & $2.2 \pm 0.1$ \\
\hline
\end{tabular}

Acknowledgements - The support by the Deutsche Forschungsgemeinschaft and the Fonds der Chemischen Intudstrie is gratefully acknowledged. In addition, we thank Dr. D. Hendisch, Bayer AG, Leverkusen, for recording the iH-NMR spectrum of 2 a and carrying out decoupling experiments, and the Union Rheinische Braunkohlen Rrartstorf AG, Hesseling, for gifts of dimethyl ether required for the preparation of benzvalene.

\section{REFERBNCBS AND FOOTNOTBS}

'H. Kessler in Methoden der organischen Chemie (Houben-Heyl-Müller) (4th Edn.). Vol. V/1d, p. 301. Thieme, Stuttgart (1972)

${ }^{2}$ R. H. Hoffmann, F. Frickel, Synthesis 1975, 444.

3 H. Adam, F. Adamsky, F. -G. Rläner, E. -M. Peters, R. Peters, H. Rebollo, W. Rüngeler, H. G. von Schnering, Chem. Ber. 116 (1983) 1848.

$4 \mathrm{R}$. Hannemann, Angew. Chem. 100 (1988) 273; Angew. Chem. Int. Ed. Enq3. 27 (1988) 284 .

'Communication: M. Christ), E. Brunn, Angew. Chem, 93 (1981) 474; Angew. Chem. Int. Ed. Engl. 20 (1981) 468 .

'M. Christl, Angew. Chem. 85 (1973) 666; Angew. Chem. Int. Ed. Engl. 12 (1973) 660 .

M. Christl, H. Leininger, P. Remmer, Chem. Ber. 117 (1984) 2963.

- Cr. footnote 2 of ref. 5 .

- M. Christl, B. Brunn, A. Rraft, H. Irngartinger, U. Huber-patz, H. Rodewald, to be submitted for publication.

10 . R. Huisgen in 1,3-Dipolar Cycloaddition Chemistry (A. Padwa, Ed.), Vol. 1, p. 1, Wiley, New York (1984). 'J. Geittner, Dissertation, Universität München (1973).

1 R. Huisgen in Methoden der organischen Chemie (Houben-Heyl-Muller) (4th Edn.), Vol. III/1, p. 99, Thieme, stuttgart (1955).

12 M. Christl, B. Mattauch, H. Irngartinger, A. Goldmann, Chem. Ber, $199(9986) 950$.

is Cf footnotes 18 and 19 of ref 12

T R. Huisgen, P. H. J. Ooms, M. Mingin, N. L. Allinger, J. Am. Chem. Soc. 102 (1980) 3951 .

13 M. Christl, G. Freitag, G. Brütrup, Chem. Ber, 111 (1978) 2307.

1. M. Christl, Angew. Chem. 93 (1981) 515; Angew. Chem. Int. Ed, Engl, 20 (1981) 529.

17 D. Hendisch in Methoden der organischen Chemie (Houben-Weyl-Müller) (4th Edn.), Vol. IV/3, Thieme, stuttgart (1971).

1. $k$. Mackenzie in The Chemistry of the Hydrazo, Azo, and Azoxy Groups is. Patai,

Ed.), Part 1, p. 329, Hiley, London (1975).

1 M. Christl, H. Leininger, B. Brunn, J. Org. Chem. 47 (1982) 661.

20 M. Christl, U. Heinemann, H. Rristof, J.Am, Chem. Soc. 97 (1975) 2299.

2 E. Brunn, Dissertation, Universitat Huraburg (1983).

$22 \mathrm{~s}$. Hoz in The Chemistry of the Cvelopropyl Group (s. Patai, z. Rappoport, Eds.), Part 2, p. 1121, Hiley, Chichester (1987)

23 L. A. Paquette, Synthesis 1975, 347 and refs. cited therein.

24M. Christ1, G. Bruntrup, Chem. Ber, 107 (1974) 3908. 